\title{
EFFECT OF DENTIN PRETREATMENT REGIMENS USING GRAPE SEED EXTRACT ON MICROSHEAR BOND STRENGTH AND COLOR STABILITY
}

\author{
Maha E. Elkorashy* and Dalia I. Sherief**
}

\begin{abstract}
Objective: To investigate the effect of $10 \%$ and $15 \%$ Proanthocyanidin (PA) rich grape seed extract (GSE) applied for 60s and 120s and removed either by wiping or rinsing on microshear bond strength $(\mu \mathrm{SBS})$ and color stability $(\Delta \mathrm{E})$.

Methods: Sound bovine incisors were used in the study. The labial surfaces were ground to expose flat dentine surfaces. The specimens were divided into 9 groups; control group without any pretreatment and 8 groups pretreated with $10 \%$ and $15 \%$ GSE, applied for 60 s and 120 s and then removed either by wiping with wet cotton or rinsing with water. Microshear bond strength ( $\mu$ SBS) was tested using a universal testing machine at a cross head speed of $0.5 \mathrm{~mm} / \mathrm{min}$. A spectrophotometer was used for color measurement $(\Delta E)$ of the specimens using CIE $\left(L^{*} a^{*} b^{*}\right)$. Data were tabulated and statistically analyzed.
\end{abstract}

Results: All pretreatment groups showed significantly higher $\mu$ SBS values than the control group which showed the lowest value $(19.63 \pm 3.07)$. Group VIII showed the highest $\mu$ SBS value $(31.96 \pm 2.77)$ and the highest $\Delta \mathrm{E}(3.14 \pm 0.38)$. All pretreatment groups showed a clinically accepted color change with a $\Delta \mathrm{E}<3.3$.

Conclusion: The use of GSE in different regimens improved resin-dentin bond strength and demonstrated clinically accepted color change. The use of $15 \%$ GSE applied for 120s and wiped with wet cotton is the recommended regimen.

KEY WORDS: Grape seed extract, dentin pretreatment, bond strength, color stability.

\section{INTRODUCTION}

The achievement of an efficient and stable bond between composite and dentin remains a challenge in restorative dentistry. Despite recent improvements in dental adhesive systems, the bonded interface remains the weakest area of the tooth colored restorations. This interface, also known as the hybrid layer, is composed of collagen

* Lecturer, Operative Dentistry Department, Faculty of Dentistry, Fayoum University.

** Lecturer, Biomaterials Department, Faculty of Dentistry, AinShams University. 
fibrils and adhesive resin that form an interlocked entanglement, providing for the basis of bonding between the bulk adhesive and the underlying intact dentin ${ }^{(1)}$.

The stability and maintenance of dentin collagen fibrils is critical for effective bonding. However, the collagen fibrils at the bottom of the hybrid layer are at the risk of exposure due to the discrepancy between the depth of acid etching and resin infiltration resulting in resin-deficient zone of unprotected collagen fibrils. The mechanical strength and stability of exposed collagen fibrils are often low ${ }^{(2)}$. As a result, the partially exposed collagen fibrils together with the adhesive resin are susceptible to variety of physical and chemical factors, including hydrolysis and enzymatic degradation ${ }^{(3,4)}$.

Researches on dentin non-collagenous proteins have demonstrated that dentin collagen fibrils contain inactive proforms of proteolytic enzymes called matrix metalloproteinases (MMPs) ${ }^{(5)}$. Those host-derived matrix metalloproteinases are a class of zinc- and calcium-dependent endopeptidases (collagenases, gelatinases, and co-elastinases) which are capable of degrading all extra-cellular matrix components ${ }^{(6)}$. They are mainly secreted by odontoblasts and are trapped within the mineralized collagen matrix during odontogenesis ${ }^{(7)}$. It has also been shown that the application of acid etching or self etching procedures can lead to activation and increased expression of MMPs, ${ }^{(8,9)}$ which plays a role in the enzymatic breakdown of the newly formed hybrid layer ${ }^{(9,10)}$.

Proanthocyanidins (PA) are naturally occurring bioflavonoids found in high concentrations in grape seed, pine bark, cranberries, lemon tree bark, and hazel nut tree leaves ${ }^{(11)}$. Proanthocyanidins possess a collagen cross-linking activity that have been shown to stimulate interfibrillar, intrafibrillar as well as intermicrofibrillar cross-links in the collagen matrix ${ }^{(12,13)}$. As a result of its cross linking effect, PA enhanced the mechanical properties of dentinal collagen and preserved the collagen matrix from degradation by exogenous collagenase $\mathrm{e}^{(10,14,15)}$. Proanthocyanidin has an inhibitory effect on MMPs $^{(16,17)}$ in addition to its low toxicity which supports its use in intraoral applications ${ }^{(18)}$.

Different concentrations of PA were used in many researches such as $0.5 \%^{(19,20)} 6.5 \%^{(14,21)}$ and $15 \%^{(2,20)}$ either to demonstrate its effect on the stiffness and stabilization of demineralized dentin ${ }^{(14,20,22,23)}$ or on the bond strength to dentin substrate ${ }^{(12,23,24)}$. A wide range of application times was recorded in many studies as seconds ${ }^{(2,20,22)}$, minutes ${ }^{(2,21,22)}$ or may extend to hours ${ }^{(19,22,23)}$. Some of these researches removed PA rich grape seed extract (GSE) by wiping with wet cotton ${ }^{(2)}$ while the others removed it by rinsing with water ${ }^{(20,21,23)}$. However, none of these researches demonstrated the interaction of all these factors with each other to recommend a specific application regimen for GSE during bonding procedures.

In addition to the demands of achieving an efficient stable bond, restorative materials that closely mimic the natural teeth appearance is becoming increasingly important. Color stability is among the factors contributing to the success of esthetic restorations. Color alteration of resin composites is a multifactorial phenomenon and is associated with intrinsic discoloration and extrinsic staining that can occur during clinical use ${ }^{(25)}$. Various elements such as surface roughness ${ }^{(26)}$, sample thickness ${ }^{(27)}$ and background color ${ }^{(28)}$ influence color perception. Proanthocyanidin belongs to a category known as condensed tannins ${ }^{(29)}$ and the dietary intake of tannin-rich foods promotes extrinsic staining ${ }^{(30)}$. The resin composite is identified as a semitransparent material. In this respect, the color of the underlying tissues can influence the esthetics of the final restoration ${ }^{(31)}$ and hence the effect of PA rich extracts on color stability is an issue of concern.

Accordingly, the current study was designed to investigate the effect of $10 \%$ and $15 \%$ concentrations of PA rich GSE applied for 60s and 
120 s and removed either by wiping with wet cotton or rinsing with water on resin-dentin microshear bond strength ( $\mu \mathrm{SBS})$ and color stability. The first null hypothesis was that application of GSE with different regimens does not affect the microshear bond strength. The second null hypothesis was that the application of GSE with different regimens does not affect the color stability.

\section{MATERIALS AND METHODS}

\section{Preparation of GSE- based preconditioners}

Proanthocyanidin rich grape seed extract based preconditioners were prepared by adding powdered 95.64\% grape seed extract (NuSci, Walnut, CA, USA) to absolute ethanol (El-Nasr Pharmaceutical Chemicals Co, Cairo, Egypt) at two different concentrations $(10 \%$ and $15 \% \mathrm{w} / \mathrm{v})$. The $\mathrm{pH}$ of the solutions was adjusted to 7.2 using $0.5 \mathrm{~mol} / \mathrm{L}$ $\mathrm{NaOH}$ (Sigma-Aldrich; St. Louis, MO, USA). The solutions were then filtered before use ${ }^{(2)}$.

\section{Specimen preparation}

A total of 135 sound extracted bovine incisors were used. The teeth were washed, scaled from adhering soft tissue, plaque and calculus and stored in distilled water at $4^{\circ} \mathrm{C}$ for not more than one month. Roots of bovine incisors were cut $2 \mathrm{~mm}$ below the cemento-enamel-junction. The crowns were mounted in self-cured acrylic resin blocks using metal mold $(2 \mathrm{~cm} \times 3 \mathrm{~cm})$. Enamel was removed by wet grinding of the labial surfaces using 80 grit sandpaper discs creating an exposed flat dentine surfaces. A uniform smear layer was then achieved by utilizing wet 600 grit sandpaper discs for 60 s.

\section{Surface pretreatment regimens}

After grinding of labial enamel, 37\% phosphoric acid etchant gel (UltraEtch®, ULTRADENT, Inc, USA) was applied to dentin for $15 \mathrm{~s}$, rinsed under running water for another $15 \mathrm{~s}$ and excess water was blotted away using cotton pellet. For the pretreatment groups, GSE was applied in one of two concentrations; either $10 \%$ or $15 \%$ using disposable microbrush applicators then left for either 60 s or 120 s and finally removed either by wiping with wet cotton or rinsing with water for $15 \mathrm{~s}$. Thus the specimens were randomly divided into 9 groups, according to the pretreatment regimen used; group I: No pretreatment (control); group II: $10 \%$ GSE, 60s, wiping; group III: $10 \%$ GSE, $60 \mathrm{~s}$, rinsing; group IV: $10 \%$ GSE, 120s, wiping; group V:10\%GSE, 120s, rinsing; group VI: 15\%GSE, 60s, wiping; group VII: 15\% GSE ,60s, rinsing; groupVIII:15\% GSE, 120s, wiping and group IX: $15 \%$ GSE, 120s, rinsing.

\section{Microshear bond strength testing ( $\mu$ SBS)}

A Total of 45 bovine incisors were used for the $\mu$ SBS test. Two coats of etch and rinse, visible-light activated bonding agent (Adper ${ }^{\mathrm{TM}}$ Single Bond Plus Adhesive, 3M ESPE, St.Paul, MN, USA) were applied on the dentin surfaces using disposable microbrush applicators with gentle rubbing for $20 \mathrm{~s}$ according to manufacturer's instructions. Gentle air streaming for $5 \mathrm{~s}$ was done to ensure complete evaporation of the adhesive solvent. Rubber microtubes of $1 \mathrm{~mm}$ diameter and $1 \mathrm{~mm}$ height (Harvard tubing, USA) were placed on the treated dentin surfaces. A maximum of two microtubes were placed on the labial surface of each bovine incisor to facilitate procedure of specimen preparation and testing with total of 10 specimens for each group. The adhesive resin was then light cured using LED light curing unit (Elipar S10 free light 3M ESPE) with light intensity $1200 \mathrm{~mW} / \mathrm{cm}^{2}$ for 10 s according to the manufacturer's instructions.

The microtubes were filled with nanofilled flowable resin composite (Filtek $^{\mathrm{TM}}$ Z350 XT Flowable Restorative, 3M ESPE, St.Paul, MN, USA). The microtubes were covered with celluloid strips (Stripmat, POLYDENTIA, CH-6805 Mezzovico, Switzerland) and each resin composite cylinder was light cured for 20 s according to the manufacturer's instructions. After curing of resin 
composite, the rubber microtubes were sectioned longitudinally using sharp scalpel and removed and the excess adhesive resin was scraped. Samples debonded during removal of rubber microtubes, were excluded. The specimens were then stored in distilled water for $24 \mathrm{~h}$ before testing.

The microshear bond strength was tested using a universal testing machine (Lloyd LR 5K, Lloyd Instruments Ltd, Hampshire, UK) with a cross head speed of $0.5 \mathrm{~mm} / \mathrm{min}$. A thin metal wire $(0.2 \mathrm{~mm}$ diameter) was looped around each resin composite cylinder and gently held flushing against the dentin at the resin-dentin interface. Each resin composite cylinder was stressed to failure, and the force required for debonding was divided by the bonded area of the specimens to express the bond strength values in $\mathrm{MPa}$.

\section{Color measurement}

A total of 90 bovine incisors were prepared, grouped and treated in the same manner as previously mentioned with a total of 10 specimens for each group. After bonding procedures, a circular split teflon mold $(8 \mathrm{~mm}$ in diameter and $2 \mathrm{~mm}$ in thickness) was placed on the labial dentin surface. The mold was filled with a nanofilled resin composite (Filtek ${ }^{\mathrm{TM}}$ Z350 XT Universal Restorative, 3M ESPE, St.Paul, MN,USA). A celluloid strip was placed on top of the mold and covered by a glass slide, pressed to extrude the excess material and obtain a uniformly smooth specimen surface. The glass slide was removed and the resin composite was cured for 20s with the light curing tip placed directly on the celluloid strip. The specimens were stored for $24 \mathrm{~h}$ before color measurement.

A spectrophotometer (Cary 5000, Agilent Technologies, USA) was used for color measurement of the specimens using CIE $\left(\mathrm{L}^{*} \mathrm{a} * \mathrm{~b}^{*}\right)$ relative to a standard illuminate D65. The color was measured for the group with no pretreatment regimen as a control and was measured for the other groups involving various pretreatment regimens. The color was measured in three coordinate dimensions of $\mathrm{L}^{*}$ (lightness), $\mathrm{a}^{*}$ green-red $\left(-\mathrm{a}^{*}=\right.$ green $\left.;+\mathrm{a}^{*}=\mathrm{red}\right)$ and $b^{*}$ blue-yellow $\left(-b^{*}=\right.$ blue; $+b^{*}=$ yellow $)$. The magnitude of total color difference between the control group and other groups subjected to various GSE pretreatment regimens is represented by a single number $\Delta \mathrm{E}^{(32)}$, where:

$$
\Delta \mathrm{E}=\left[\left(\Delta \mathrm{L}^{*}\right)^{2}+\left(\Delta \mathrm{a}^{*}\right)^{2}+\left(\Delta \mathrm{b}^{*}\right)^{2}\right]^{1 / 2}
$$

\section{Scanning electron microscope (SEM) observation}

A representative sample from each group was used for SEM observation of resin-dentine interface. The teeth were sectioned longitudinally using a diamond disc under copious water coolant. The sectioned surfaces were flattened and smoothed using sandpaper discs with ascending grits 320, 600 , and 1200 respectively. The specimens were acid etched using 37\% phosphoric acid gel for 20 s and rinsed for another 20s to remove smear layer. The specimens were then immersed in a $5.25 \%$ sodium hypochlorite for $10 \mathrm{~min}$ to remove collagen exposing the hybrid layer and resin tags. The specimens were washed under running water and dried in a desiccator containing anhydrous silica gel at $37^{\circ} \mathrm{C}$ for $24 \mathrm{~h}$. The specimens were gold sputter coated (EMITECH K550X sputter coater, England) and the interfacial zone with dentin was examined using SEM (FEI Company, Netherland) Model Quanta 250 Field Emission Gun (FEG) at magnification $2000 \mathrm{X}$.

\section{Statistical analysis}

Statistical analysis was performed with IBM ${ }^{\circledR}$ SPSS ${ }^{\circledR}$ (SPSS Inc., IBM Corporation, NY, USA) Statistics Version 22 for Windows. Data were presented as means and standard deviations (SD). Data explored for normality using Kolmogorov-Smirnov and Shapiro-Wilk tests. All tested parameters showed a parametric distribution. One Way-ANOVA used to study the effect of different GSE concentrations in different 
application times and removal techniques on mean Shear bond (MPa). Duncan's post-hoc test was used for pairwise comparison between the means when ANOVA test is significant. Independent t-test used to study the effect of GSE concentration in different application times and removal techniques on mean $\Delta$ E. One Way-ANOVA was used to compare between different groups for microshear bond strength (MPa) and color stability $(\Delta \mathrm{E})$. The significance level was set at $p \leq 0.05$ for all analyses.

\section{RESULTS}

\section{Microshear bond strength results}

The results of $\mu \mathrm{SBS}$ as shown in table (1) revealed that control group showed the lowest bond strength value $(19.63 \pm 3.07)$ with significant difference from all other groups. Regarding the effect of GSE concentrations, no significant differences were recorded between $10 \%$ and $15 \%$ GSE on $\mu$ SBS values in all tested groups except in the group of $120 \mathrm{~s}$ application time and wiping removal technique where the 15\% GSE group showed a significantly higher $\mu$ SBS $(31.96 \pm 2.77)$ than $10 \%$ GSE (26.20 \pm 3.08$)$. No significant difference was recorded between different groups treated with $10 \%$ GSE concentration while those treated with of $15 \%$ concentration, the group of 120 s application time and wiping technique showed the highest $\mu \mathrm{SBS}$ value.

TABLE (1) Means and standard deviations (SD) of $\mu$ SBS (MPa) for different GSE concentrations at different application times and removal techniques:

\begin{tabular}{|c|c|c|c|c|c|c|c|c|}
\hline & & \multicolumn{2}{|c|}{ Control } & \multicolumn{2}{|c|}{$10 \%$ GSE } & \multicolumn{2}{|c|}{$15 \% \mathrm{GSE}$} & \multirow{2}{*}{$\mathrm{p}$-value } \\
\hline & & Mean & $\mathrm{SD}$ & Mean & SD & Mean & SD & \\
\hline \multirow{2}{*}{$60 \mathrm{~s}$} & Wiping & $19.63^{\mathrm{a}}$ & 3.07 & $26.07^{\mathrm{bA}}$ & 2.38 & $24.59^{\mathrm{bA}}$ & 4.28 & $\leq 0.001 *$ \\
\hline & Rinsing & $19.63^{\mathrm{a}}$ & 3.07 & $24.40^{\mathrm{bA}}$ & 4.15 & $23.14^{\mathrm{bA}}$ & 2.81 & $0.011 *$ \\
\hline \multirow{2}{*}{$120 \mathrm{~s}$} & Wiping & $19.63^{\mathrm{a}}$ & 3.07 & $26.20^{\mathrm{bA}}$ & 3.08 & $31.96^{\mathrm{cB}}$ & 2.77 & $\leq 0.001 *$ \\
\hline & Rinsing & $19.63^{\mathrm{a}}$ & 3.07 & $25.52^{\mathrm{bA}}$ & 2.78 & $26.19^{\mathrm{bA}}$ & 3.93 & $\leq 0.001 *$ \\
\hline \multicolumn{4}{|c|}{$p$-value } & \multicolumn{2}{|c|}{$0.576 \mathrm{NS}$} & \multicolumn{2}{|c|}{$\leq 0.001 *$} & \\
\hline
\end{tabular}

Different letters (lower case in rows and upper case in columns) are significantly different at p $\leq 0.05$.

TABLE (2) Means and standard deviations (SD) of color stability $(\Delta \mathrm{E})$ for different GSE concentrations at different application times and removal techniques:

\begin{tabular}{|c|c|c|c|c|c|c|}
\hline & & \multicolumn{2}{|c|}{$10 \% \mathrm{GSE}$} & \multicolumn{2}{|c|}{$15 \% \mathrm{GSE}$} & \multirow{2}{*}{ p-value } \\
\hline & & Mean & SD & Mean & SD & \\
\hline \multirow{2}{*}{$60 \mathrm{~s}$} & Wiping & $1.80^{\mathrm{aA}}$ & 0.73 & $2.45^{\mathrm{aA}}$ & 0.82 & $0.364 \mathrm{NS}$ \\
\hline & Rinsing & $1.53^{\mathrm{aA}}$ & 0.68 & $2.20^{\mathrm{aA}}$ & 0.49 & $0.238 \mathrm{NS}$ \\
\hline \multirow{2}{*}{$120 \mathrm{~s}$} & Wiping & $2.24^{\mathrm{aA}}$ & 0.24 & $3.14^{\mathrm{bA}}$ & 0.38 & $0.027 *$ \\
\hline & Rinsing & $1.98^{\mathrm{aA}}$ & 0.36 & $2.80^{\mathrm{bA}}$ & 0.35 & $0.048^{*}$ \\
\hline \multicolumn{2}{|c|}{$\mathrm{p}$-value } & \multicolumn{2}{|c|}{$0.477 \mathrm{NS}$} & \multicolumn{2}{|c|}{$0.248 \mathrm{NS}$} & \\
\hline
\end{tabular}

Different letters (lower case in rows and upper case in columns) are significantly different at p $\leq 0.05$. 


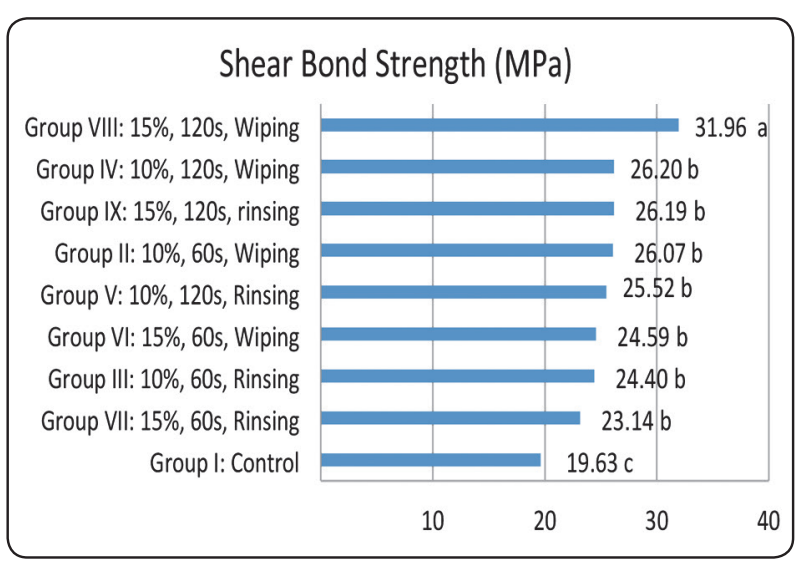

Fig. (1): Histogram showing the $\mu \mathrm{SBS}$ (MPa) for all tested groups

Means with different letters are significantly different at $p \leq 0.05$.

Figure (1) showed that the control group recorded the significantly lowest mean $\mu \mathrm{SBS}$ value $(19.63 \pm 3.07)$ while group VIII showed the significantly highest mean $\mu$ SBS $(31.96 \pm 2.77)$. The other tested groups were significantly higher than the control group and significantly lower than group VIII, with no significant differences between them.

\section{Color measurement results:}

Color stability results shown in table (2) demonstrated that the use of $15 \%$ GSE in combination with $120 \mathrm{~s}$ and wiping technique revealed a significantly higher $\Delta \mathrm{E}(3.14 \pm 0.38)$ than the $10 \%$ GSE $(2.24 \pm 0.24)$. Also $15 \%$ GSE showed significantly higher $\Delta \mathrm{E}$ than $10 \%$ with 120 s and rinsing technique with a value of $(2.80 \pm 0.35)$ and $(1.98 \pm 0.36)$ respectively. On the other hand, no significant differences were recorded between $10 \%$ and $15 \%$ GSE at 60 s application time using either wiping or rinsing techniques.

Figure (2) illustrated the comparison between

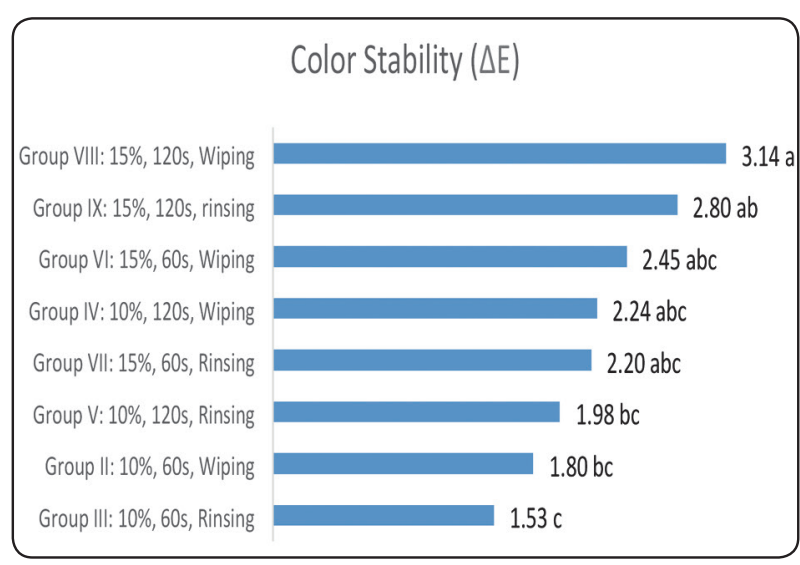

Fig. (2): Histogram showing the color stability $(\Delta \mathrm{E})$ for all tested groups

Means with different letters are significantly different at $p \leq 0.05$.

color stability of different groups in a descending manner. Group VIII showed the highest $\Delta \mathrm{E}$ mean value (3.14) followed by group IX (2.80) with no significant difference between them. However, group III represented the lowest $\Delta \mathrm{E}$ mean value (1.53) among all groups with significant difference from group VIII and group IX. No significant differences were recorded between other tested groups. All tested groups showed $\Delta \mathrm{E}<3.3$ which is considered a clinically accepted color change.

\section{Scanning electron microscopic observation}

The SEM images (Fig. 3) show longitudinal sections of the resin/dentin interface for different groups. All groups showed a uniform hybrid layer formation. Resin tags appeared obvious in all groups but with different lengths, thicknesses and densities. Group V (Fig. 3e) and group VI (Fig. 3f) demonstrated thin and scarce resin tags. As for group VIII (Fig. 3h), the resin tags appeared numerous, dense and uniform compared to any other group. 


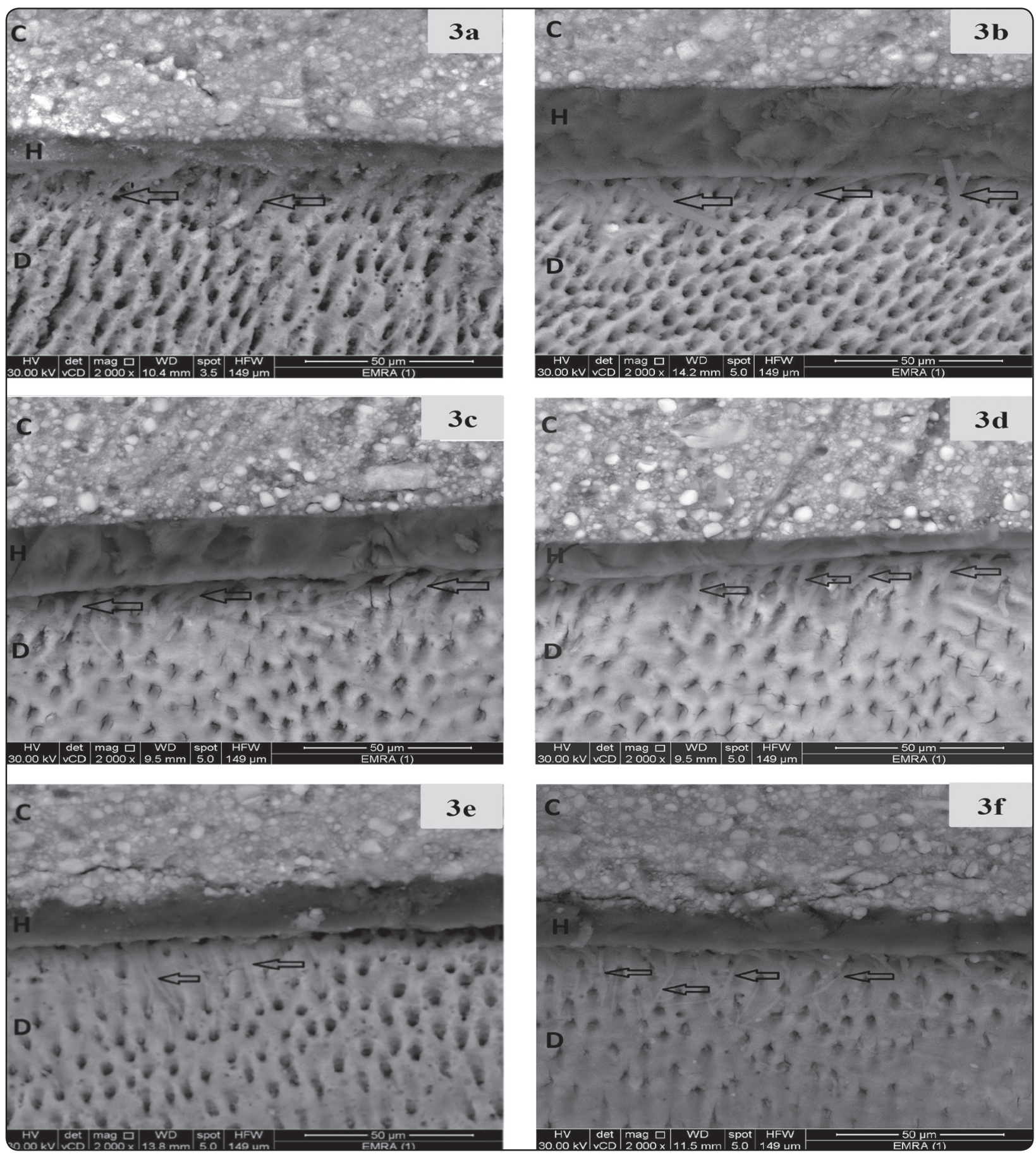



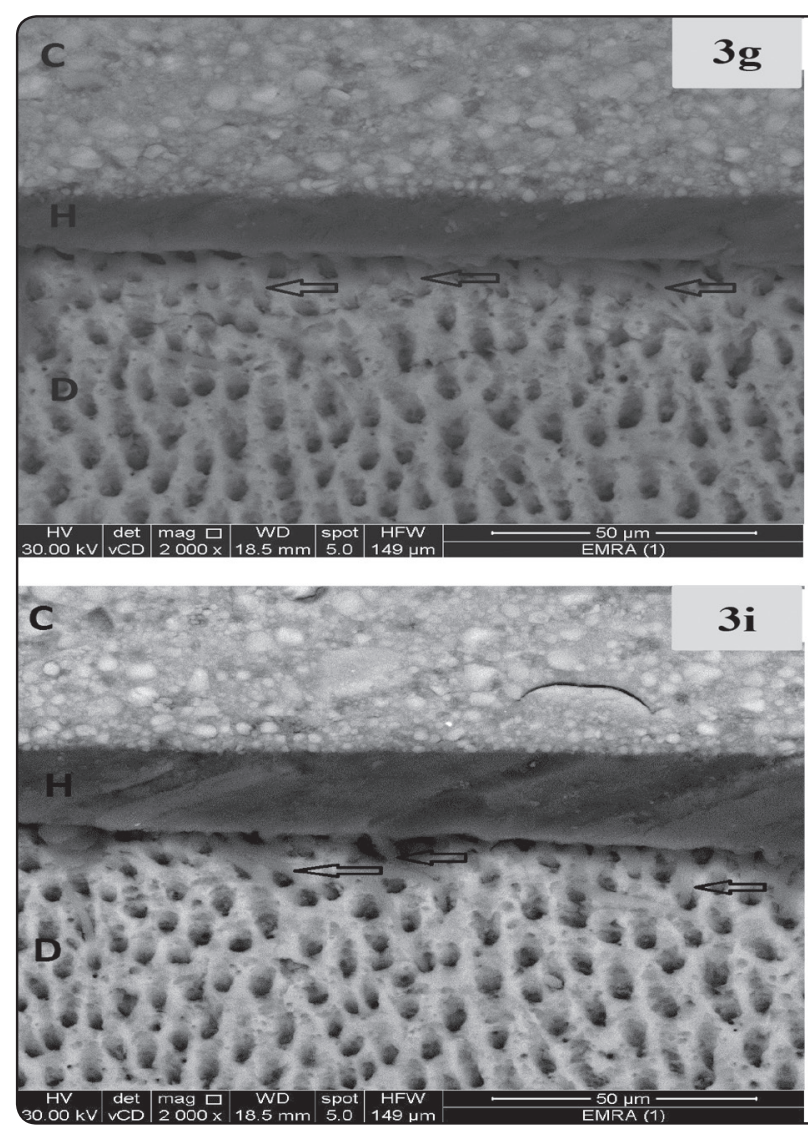

\section{DISCUSSION}

Proanthocyanidins are of particular interest, not only because they are non-toxic collagen crosslinkers $^{(18)}$, but also their building blocks, such as catechin and epigallocatechin gallate, have been identified as potent collagenase inhibitors ${ }^{(33)}$. Therefore, PA could improve the enzymatic stability of dentin collagen synergistically via both approaches.

Previous studies, ${ }^{(10,34)}$ performed using the PA as an additive to the bonding agent, showed a reduced quality of the hybrid layer together with lower microtensile bond strength ( $\mu$ TBS) values compared to direct application of PA to dentin as a separate step. This is presumably due to the free radical scavenging effect of $\mathrm{PA}$ which might inhibit the adhesive resin polymerization ${ }^{(35)}$. Therefore in the current study, Grape seed extract rich in PA was

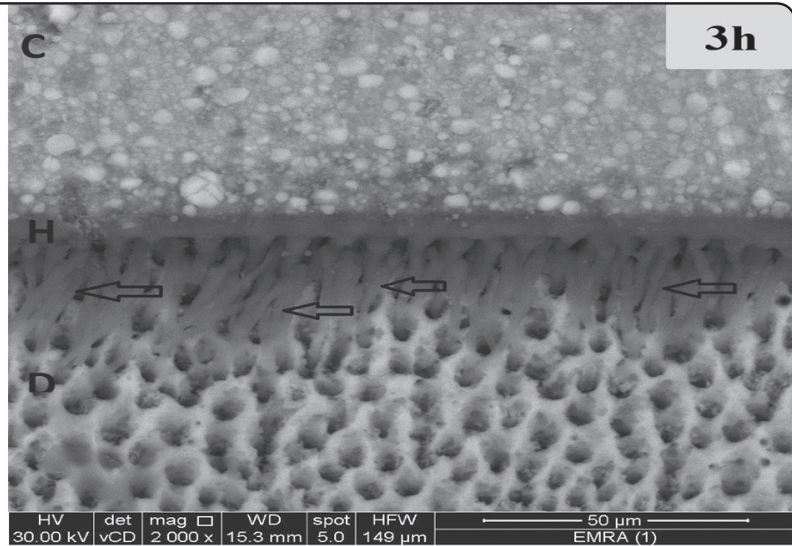

Fig. 3 (a-i) reveals SEM image 2000X of resin/dentin interface for all tested groups. (C) denotes resin composite, (H) denotes hybrid layer, (D) denotes dentin and the arrows denote resin tags.

Fig. 3a: reveals group I (control group); Fig. 3b: reveals group II; Fig. 3c: reveals group III; Fig. 3d: reveals group IV; Fig. 3e: reveals group V; Fig. 3f: reveals group VI; Fig. 3g: reveals group VII; Fig. 3h: reveals group VIII; Fig. 3i: reveals group IX.

introduced to the bonding procedure by means of a separate pretreatment rather than addition to the bonding agent. Such separate step not only avoids the adverse effect on the polymerization of the adhesives used, but also allows incorporation of PA in higher concentrations ${ }^{(2)}$. However, an extra step might complicate the clinical bonding procedures and requires a longer chair side time.

Proanthocyanidin has been shown to have a high affinity to proteins and bind to the collagen matrix, thereby displacing water molecules ${ }^{(36)}$. It interacts with proteins in four different ways: 1) covalent interactions, 2) ionic interactions, 3) hydrogen bonding interactions, or 4) hydrophobic interactions ${ }^{(23,37)}$. A study using Fourier transform infrared spectroscopy also showed that PA promoted hydrogen bond formation in type I collagen ${ }^{(38)}$ which represents $90 \%$ of the organic matrix of dentin ${ }^{(39)}$. 
The formation of hydrogen bonding between the protein amide carbonyl group of dentine collagen and PA could be measured by the Hansen solubility parameter $\delta \mathrm{H}^{(40)}$. The $\delta \mathrm{H}$ values of ethanol and acetone are lower than that of distilled water, thereby less hydrogen bonding sites would be occupied by the solvent leaving more available hydrogen bonding sites. This allows more hydrogen bonding between PA-collagen or collagen-collagen molecules inducing more collagen cross-linking and improved mechanical properties ${ }^{(41)}$.

Hagerman and Klucher, ${ }^{(42)}$ reported that ethanol could decrease the dielectric constant of the media to stimulate PA and collagen interactions and enhance the stability of hydrogen bonds. Therefore ethanol may be a preferable solvent for PA-based preconditioners and hence, it was selected to be the media of dissolution of GSE in the current study. The adhesive used in this study was also ethanol based to avoid discrepancy of the solvents that may negatively affect the bond strength ${ }^{(2)}$.

Other researches ${ }^{(14,15)}$ reported that PA treatment could increase the mechanical properties of demineralized dentin in a concentration and time dependent manner. Higher concentration of PAbased agents and relatively shorter treatment durations were used in this study to make it more clinically relevant as well as effective. Results of the present study revealed that transient PA preconditioning significantly increased the resindentin bond strength regardless the pretreatment regimen (table 1). Thus the first null hypothesis was rejected. This finding was in agreement with many researches ${ }^{(2,14,15)}$ which reported that pretreating the demineralized dentin with PA-based agents was effective in increasing the mechanical properties of dentin matrix, enhancing the resin-dentin microtensile bond strength ( $\mu \mathrm{TBS}$ ) and decreasing the enzymatic degradation compared to the nontreated groups. Proanthocyanidin was proven to have an extraordinarily effect in stabilizing demineralized dentin collagen against enzymatic challenges when applied in a clinically relevant manner $^{(22)}$. It was also found that treatment by PAbased preconditioners in a clinically applicable duration increased the cross-linking degree and ultimate tensile strength of demineralized dentin ${ }^{(13)}$.

Although some studies ${ }^{(14,15)}$ mentioned that PA pretreatment effects are concentration and time dependent, the results of the current study showed the opposite. There was no significant difference in the $\mu$ SBS at different pretreatment regimens, with the exception of group VIII. This might be justified by the idea that using such high concentrations and clinically applicable times might produce an optimum PA effect. Thus using either $10 \%$ or $15 \%$ PA concentrations for either 60 s or 120 s might not produce a significant change in the $\mu$ SBS results. Such conclusion was supported by Fang et $a l^{(2)}$, who found no significant difference in resin-dentin $\mu$ TBS for both $10 \%$ and $15 \%$ PA concentrations when applied for $120 \mathrm{~s}$. No significant difference was also detected between 60s and 120s application times at $15 \%$ GSE concentration. Another study stated that no significant differences were observed between the 60s and 120s application times for a $10 \%$ PA concentration regarding the resin-dentin $\mu \mathrm{TBS}^{(24)}$.

Group VIII showed the significantly highest resin-dentin bond strength value in comparison to all other groups (Figure 1). An explanation for such finding might be due to the interaction of the higher concentration (15\%), longer application time (120s) and the less vigorous removal technique (wiping) which might lead to the persistence of a considerable amount of PA in the dentin collagen network. Such residual PA might have caused further collagen crosslinking and collagenase enzymes inhibition, leading to a significantly higher $\mu$ SBS compared to other tested groups. SEM images supported such finding, where group VIII showed the densest, most numerous and uniform resin tags among all other groups (Fig. 3h). 
The $\mathrm{L}^{*} \mathrm{a} * \mathrm{~b} *$ system scale, developed by CIE, is commonly used to describe color characteristics of an object based on three parameters: $\mathrm{L}^{*}, \mathrm{a}^{*}$, and $\mathrm{b}^{*}$. Color change is described quantitatively in $\Delta \mathrm{E}$ units, which combines changes in each of the individual parameters into a single value. The results of color stability (table 2 ) revealed that the use of $15 \%$ GSE showed a significantly higher $\Delta \mathrm{E}$ than $10 \%$ GSE when applied for 120s with both removal techniques and accordingly the second null hypothesis was also rejected. Proanthocyanidinrich extracts can cause a brownish discoloration of dentin. This reported discoloration may be related to the content of polymeric, high molecular weight PA and their oxidation products ${ }^{(43)}$. Although GSE concentration showed significant change in $\Delta \mathrm{E}$ results, color change caused by all the applied pretreatment regimens was clinically imperceptible as they all show $\Delta \mathrm{E}<3.3$. Such $\Delta \mathrm{E}$ value does not necessitate restoration replacement ${ }^{(44)}$.

The results of color measurement might support our assumption that the interaction between the higher concentration of GSE and higher application time in combination with the less vigorous removal technique as wiping represented in group VIII resulted in higher $\mu$ SBS and higher $\Delta \mathrm{E}$ results. On contrary, the least concentration and application time with more vigorous removal technique as rinsing represented in group III resulted in the lowest value in $\Delta \mathrm{E}$ in conjunction with a minimum microshear bond strength value. Although, group VIII showed the highest $\mu \mathrm{SBS}$ value, it also recorded the highest $\Delta E$ value and hence, the goal of the ongoing efforts is to study the effect of higher concentrations of GSE on bond strength with emphasis on its effect on color stability using different composite thicknesses and translucencies.

\section{CONCLUSIONS}

Within the limitations of the present study we can conclude that:
1- Application of GSE in different regimens improved resin-dentin bond strength.

2- Different pretreatment regimens of GSE demonstrated clinically accepted color change.

3- The use of $15 \%$ GSE for 120 s and wiping with wet cotton demonstrated superior bond strength with imperceptible color change.

\section{REFERENCES}

1. Nakabayashi N, Kojima K, Masuhara E. The promotion of adhesion by the infiltration of monomers into tooth substrates. J Biomed Mater Res 1982; 16:265-273.

2. Fang M, Liu R, Xiao Y, Li F, Wang D, Hou R, Chen J. Biomodification to dentin by a natural cross linker improved the resin-dentin bonds. J Dent 2012; 40:458-466.

3. Kostoryz EL, Dharmala K, Ye Q, Wang Y, Huber J, Park JG, Snider G, Katz JL, Spencer P. Enzymatic biodegradation of HEMA/bisGMA adhesives formulated with different water content. J Biomed Mater Res B Appl Biomater 2009; 88:394-401.

4. Tay FR, Pashley DH. Have dentin adhesives become too hydrophilic? J Can Dent Assoc 2003; 69:726-731.

5. Perdigao J, Reia A, Loguerico AD. Dentin adhesion and MMPs: A comprehensive review. J Esthet Restor Dent 2013; 25:219-241.

6. Carhillo MR, Carvalho RM, de Goes MF, di Hipólito V, Geraldeli S, Tay FR, Pashley DH, Tjäderhane L. Chlorhexidine preserves dentin bond in vitro. J Dent Res 2007; 86:90-94.

7. Mazzoni A, Papa V, Nato F, Carrilho M, Tja“derhane L, Ruggeri A, Jr Gobbi P, Mazzotti G, Tay FR, Pashley DH, Breschi L. Immunohistochemical and biochemical assay of MMP-3 in human dentine. J Dent 2011; 39:231-237.

8. Lehmann N, Debret R, Romeas A, Magloire H, Degrange M, Bleicher F, Sommer P, Seux D. Self-etching increases matrix metalloproteinase expression in the dentin-pulp complex. J Dent Res 2009; 88:77-82.

9. Pashley DH, Tay FR, Yiu C, Hashimoto M, Breschi L, Carvalho RM, Ito S. Collagen degradation by host-dervied enzymes during aging. J Dent Res 2004; 83:216-221.

10. Green B, Yao X, Ganguly A, Xu C, Dusevich V, Walker MP, Wang Y. Grape seed proanthocyanidins increase 
collagen biodegradation resistance in the dentin/adhesive interface when included in an adhesive. J Dent 2010; 38:908-915.

11. Fine AM. Oligomeric proanthocyanidin complexes: History, structure, and phytopharmaceutical applications. Altern Med Rev 2000; 5:144-151.

12. Al-Ammar A, Drummond JL, Bedran-Russo AK. The use of collagen cross-linking agents to enhance dentin bond strength. J Biomed Mater Res B Appl Biomater 2009; 91:419-424.

13. Liu R, Fang M, Xiao Y, Li F, Yu L, Zhao S, Shen L, Chen J. The effect of transient proanthocyanidins preconditioning on the cross-linking and mechanical properties of demineralized dentin. J Mater Sci-Mater Med 2011; 22:2403-2411.

14. Bedran-Russo AK, Pashley DH, Agee K, Drummond JL, Miescke KJ. Changes in stiffness of demineralized dentin following application of collagen cross linkers. J Biomed Mater Res B Appl Biomater 2008; 86:330-334.

15. Castellan CS, Pereira PN, Grande RH, Bedran-Russo AK. Mechanical characterization of proanthocyanidin-dentin matrix interaction. Dent Mater 2010;26:968-973

16. Epasinghe DJ, Yiu CKY, Burrow MF, Hiraishi N, Tay FR. The inhibitory effect of proanthocyanidin on soluble and collagen-bound proteases. J Dent 2013; 41:832- 839.

17. La VD, Howell AB, Grenier D. Cranberry proanthocyanidins inhibit MMP production and activity. J Dent Res 2009; 88:627-632.

18. Yamakoshi J, Saito M, Kataoka S, Kikuchi M. Safety evaluation of proanthocyanidin-rich extract from grape seeds. Food Chem Toxicol 2002; 40:599-607.

19. Bedran-Russo AK, Pereira PN, Duarte WR, Drummond JL, Yamauchi M. Application of cross linkers to dentin collagen enhances the ultimate tensile strength. J Biomed Mater Res B Appl Biomater 2007; 80:268-272.

20. Liu Y, Wang Y. Proanthocyanidins' efficacy in stabilizing dentin collagen against enzymatic degradation: MALDITOF and FTIR analyses. J Dent 2013; 41:535- 542.

21. Srinivasulu S, Vidhya S, Sujatha M, Mahalaxmi S. Shear bond strength of composite to deep dentin after treatment with two different collagen crosslinking agents at varying time intervals. Oper Dent 2012; 37:485-491.

22. Liu Y, Chena M, Yao X, Xu C, Zhanga Y, Wanga Y. Enhancement in dentin collagen's biological stability after proanthocyanidins treatment in clinically relevant time periods. Dent Mater 2013; 29:485-492.

23. Macedo GV, Yamauchi M, Bedran-RussoAK. Effects of chemical cross-linkers on caries affected dentin bonding. J Dent Res 2009; 88:1096-1100.

24. Liu RR, Fang M, Zhang L, Tang CF, Qi Dou, Chen JH. Anti-proteolytic capacity and bonding durability of proanthocyanidin-biomodified demineralized dentin matrix. Int J Oral Sci 2014; 6:168-174.

25. De Carvalho Pires-de-Souza F, Garcia L, Roselino L, Naves L. Color stability of silorane-based composites submitted to accelerated artificial ageing-An in situ study. J Dent 2011; 39:18-24.

26. Ghinea R, Ugarte-Alvan L, Yebra A, Pecho OE, Paravina RD, Perez Mdel M. Influence of surface roughness on the color of dental-resin composites. J Zhejiang Univ Sci B $2011 ; 12: 552-562$.

27. Schmeling M, Meyer-Filho A, de Andrada MA, Baratieri LN. Chromatic influence of value resin composites. Oper Dent 2010; 35:44-49.

28. Ardu S, Braut V, Gutemberg D, Krejci I, Dietschi D, Feilzer AJ. A long-term laboratory test on staining susceptibility of esthetic composite resin materials. Quintessence Int 2010; 41:695-702.

29. Dixon RA, Xie DY, Sharma SB. Proanthocyanidins: a final frontier in flavonoid research? New Phytol 2005; 165:9-28.

30. Watts A, Addy M. Tooth discolouration and staining: a review of the literature. Br Dent J 2001; 190:309-316.

31. Gaintantzopoulou M, Kakaboura A, Loukidis M, Vougiouklakis G. A study on color stability of self etching and etch-and-rinse adhesives. J Dent 2009; 37:390-396.

32. Commission Internationale de L'Eclairage. Recommendations on uniform color spaces, color difference equations, psychometric color terms. CIE. Pub 1979; 15:9-12.

33. Madhan B, Krishnamoorthy G, Rao JR, Nair BU. Role of green tea polyphenols in the inhibition of collagenolytic activity by collagenase. Int J Biol Macromol 2007; 41:16-22.

34. Hechler B, Yao X, Wang Y. Proanthocyanidins alter adhesive/dentin bonding strengths when included in a bonding system. Am J Dent 2012; 25:276-280. 
35. Epasinghe DJ, Yiu CKY, Burrow MF, Tay FR, King NM. Effect of proanthocyanidin incorporation into dental adhesive resin on resin-dentine bond strength.J Dent2012; 40:173-180.

36. He L, Mu C, Shi J, Zhang Q, Shi B, Lin W. Modification of collagen with a natural cross-linker, procyanidin. Int J Biol Macromol 2011; 48:354-359.

37. Xie Q, Bedran-Russo AK, Wu CD. In vitro remineralization effects of grape seed extract on artificial root caries. J Dent 2008; 36:900-906.

38. Botta SB, Ana PA, Santos MO, Zezell DM, Matos AB. Effect of dental tissue conditioners and matrix metalloproteinase inhibitors on type I collagen microstructure analyzed by Fourier transform infrared spectroscopy. J Biomed Mater Res B Appl Biomater 2012; 100:10091016.

39. Marshall GW Jr. Dentin: microstructure and characterization. Quintessence Int 1993; 24:606-617.
40. Chappelow CC, Power MD, Bowles CQ, Miller RG, Pinzino CS, Eick JD. Novel priming and crosslinking systems for use with isocyanatomethacrylate. Dent Mater 2000; 16:396-405.

41. Nalla RK, Balooch M, Ager 3rd JW, Kruzic JJ, Kinney JH, Ritchie RO. Effects of polar solvents on the fracture resistance of dentin: role of water hydration. Acta Biomater 2005; 1:31-43.

42. Hagerman AE, Klucher KM. Tannin-protein interactions Prog Clin Biol Res 1986; 213:67-76.

43. Bedran-Russo AK, Pauli GF, Chen SN, McAlpine J, Castellan CS, Phansalkar RS, Aguiar TR, Vidal CMP, Napotilano JG, Nam JW, Leme AA. Dentin biomodification: strategies, renewable resources and clinical applications. Dent Mater 2014; 30:62-76.

44. Fontes S, Fernandez M, Moura C, Meireles S. Color stability of nanofill composite: Effect of different immersion media. J Appl Oral Sci 2009; 17:388-391. 